\title{
Long-term functional outcome of distal radius fractures is associated with early post-fracture bone stiffness of the fracture region
}

Citation for published version (APA):

Heyer, F. L., de Jong, J. J. A., Willems, P. C., Arts, J. J., Bours, S. G. P., van Kuijk, S. M. J., Poeze, M., Geusens, P. P., van Rietbergen, B., \& van den Bergh, J. P. (2019). Long-term functional outcome of distal radius fractures is associated with early post-fracture bone stiffness of the fracture region: An HR-pQCT exploratory study. Bone, 127, 510-516. https://doi.org/10.1016/j.bone.2019.06.013

Document status and date:

Published: 01/10/2019

DOI:

10.1016/j.bone.2019.06.013

Document Version:

Publisher's PDF, also known as Version of record

\section{Document license:}

Taverne

Please check the document version of this publication:

- A submitted manuscript is the version of the article upon submission and before peer-review. There can be important differences between the submitted version and the official published version of record.

People interested in the research are advised to contact the author for the final version of the publication, or visit the DOI to the publisher's website.

- The final author version and the galley proof are versions of the publication after peer review.

- The final published version features the final layout of the paper including the volume, issue and page numbers.

Link to publication

\footnotetext{
General rights rights.

- You may freely distribute the URL identifying the publication in the public portal. please follow below link for the End User Agreement:

www.umlib.nl/taverne-license

Take down policy

If you believe that this document breaches copyright please contact us at:

repository@maastrichtuniversity.nl

providing details and we will investigate your claim.
}

Copyright and moral rights for the publications made accessible in the public portal are retained by the authors and/or other copyright owners and it is a condition of accessing publications that users recognise and abide by the legal requirements associated with these

- Users may download and print one copy of any publication from the public portal for the purpose of private study or research.

- You may not further distribute the material or use it for any profit-making activity or commercial gain

If the publication is distributed under the terms of Article $25 \mathrm{fa}$ of the Dutch Copyright Act, indicated by the "Taverne" license above, 
Full Length Article

\title{
Long-term functional outcome of distal radius fractures is associated with early post-fracture bone stiffness of the fracture region: An HR-pQCT exploratory study
}

\author{
F.L. Heyer ${ }^{\mathrm{a}, \mathrm{b}, \mathrm{c}, *}$, J.J.A. de Jong ${ }^{\mathrm{d}}$, P.C. Willems, ${ }^{\mathrm{e}, \mathrm{f}}$, J.J. Arts ${ }^{\mathrm{e}, \mathrm{f}}$, S.G.P. Bours ${ }^{\text {g }}$, S.M.J. van Kuijk ${ }^{\mathrm{h}}$, \\ M. Poeze ${ }^{\mathrm{a}, \mathrm{b}}$, P.P. Geusens ${ }^{\mathrm{e}, \mathrm{g}, \mathrm{i}}$, B. van Rietbergen ${ }^{\mathrm{j}}$, J.P. van den Bergh ${ }^{\mathrm{a}, \mathrm{c}, \mathrm{g}, \mathrm{i}}$ \\ ${ }^{\text {a }}$ Research School NUTRIM, Maastricht University, the Netherlands \\ ${ }^{\mathrm{b}}$ Department of Surgery, Maastricht University Medical Center, the Netherlands \\ ${ }^{\mathrm{c}}$ Department of Internal Medicine, VieCuri Medical Center Venlo, the Netherlands \\ ${ }^{\mathrm{d}}$ Department of Radiology, Maastricht University Medical Center, the Netherlands \\ ${ }^{\mathrm{e}}$ Research school CAPHRI, Maastricht University, the Netherlands \\ ${ }^{\mathrm{f}}$ Department of Orthopedic Surgery, Maastricht University Medical Center, the Netherlands \\ ${ }^{g}$ Department of Rheumatology, Maastricht University Medical Center, the Netherlands \\ ${ }^{\mathrm{h}}$ Department of Clinical Epidemiology \& Medical Technology Assessment, Maastricht University Medical Center, the Netherlands \\ ${ }^{\mathrm{i}}$ Faculty of Medicine and Life Sciences, Hasselt University, Belgium \\ ${ }^{\mathrm{j}}$ Faculty of Biomedical Engineering, Eindhoven University of Technology, the Netherlands
}

\section{A R T I C L E I N F O}

\section{Keywords:}

Fracture healing

Functional outcome

HR-pQCT

Finite element analysis

\begin{abstract}
A B S T R A C T
Identifying determinants of long-term functional outcome after a distal radius fracture is challenging. Previously, we reported on the association between early HR-pQCT measurements and clinical outcome 12 weeks after a conservatively treated distal radius fracture. We extended the follow-up and assessed functional outcome after two years in relation to early HR-pQCT derived bone parameters.

HR-pQCT scans of the fracture region were performed in 15 postmenopausal women with a distal radius fracture at 1-2 (baseline), 3-4 weeks and 26 months post-fracture. Additionally, the contralateral distal radius was scanned at baseline. Bone density, micro-architecture parameters and bone stiffness using micro-finite element analysis ( $\mu$ FEA) were evaluated. During all visits, wrist pain and function were assessed using the patient-rated wrist evaluation questionnaire (PRWE), quantifying functional outcome with a score between 0 and 100 .

Two-year PRWE was associated with torsional and bending stiffness 3-4 weeks post-fracture $\left(R^{2}: 0.49\right.$, $\mathrm{p}=0.006$ and $\mathrm{R}^{2}: 0.54, \mathrm{p}=0.003$, respectively). In contrast, early micro-architecture parameters of the fracture region or contralateral bone parameters did not show any association with long-term outcome.

This exploratory study indicates that HR-pQCT with $\mu$ FEA performed within four weeks after a distal radius fracture captures biomechanical fracture characteristics that are associated with long-term functional outcome and therefore could be a valuable early outcome measure in clinical trials and clinical practice.
\end{abstract}

\section{Introduction}

A fracture of the distal radius is one of the most frequently occurring fractures, with a reported incidence of 39.7 per 10,000 person-years in women over 50 years old [1] and accounts for $30 \%$ of the patients invited to the fracture liaison service (FLS) [2].

Non- or minimally displaced and stable distal radius fractures in postmenopausal women are usually treated by cast immobilization [3]. However, functional outcome of these fractures is highly variable and cannot be accounted for by fracture classification alone [4,5]. Numerous studies have been conducted to find predictors of long-term outcome after a distal radius fracture [6,7], but this has not yet led to a clinically implementable guideline [8].

Using high-resolution peripheral quantitative computed tomography (HR-pQCT) scans obtained during the early phases of fracture healing, we previously showed that a better functional outcome after 12 weeks was associated with an early increase in torsional stiffness and trabecular bone mineral density and an early decrease in trabecular

\footnotetext{
* Corresponding author at: Maastricht University Medical Center, Department of General Surgery, P. Debyelaan 25, 6229, HX, Maastricht, the Netherlands.

E-mail address: f.heyer@maastrichtuniversity.nl (F.L. Heyer).
} 
separation [9].

It is known that bone remodeling, the last phase of fracture healing, continues for months or even years after a fracture [10]. Furthermore, it has also been proposed that the duration of follow-up for the functional outcome of a distal radius fracture should be at least 1 year [11]. We therefore extended our 12-week study with an additional long-term follow-up visit 2 years post-fracture.

The objective of this exploratory cohort study was to assess the association between long-term functional outcome (pain and disability) after a distal radius fracture and early HR-pQCT-derived bone density, structural parameters, and calculated stiffness and their early changes.

\section{Material and methods}

\subsection{Study population and design}

In the original cohort study [9,12], 20 postmenopausal women visiting the emergency room of the Maastricht University Medical Center (the Netherlands) with a unilateral distal radius fracture between September 2011 and August 2012 were included. Patients requiring surgical treatment were excluded. Further in- and exclusion criteria are presented in Table 1 . Standard clinical care as per the national guidelines consisted of fracture reduction if indicated, cast treatment and referral to the FLS for screening on osteoporosis using DXA [2]. Study participation (or results thereof) did not affect the decision at the FLS to start treatment for osteoporosis, if diagnosed.

Of these 20 included patients, 18 completed the initial follow-up period with visits at 1 to 2 weeks (visit 1), 3 to 4 weeks (visit 2), 6 to 8 weeks (visit 3) and 12 weeks (visit 4) post-fracture. These patients were invited to participate in a long-term follow-up visit 2 years later.

Both the original 12-week study and this long-term follow-up visit were approved by an independent Medical Ethics Committee (protocol registration number NTR3821). Study participants signed an additional informed consent form before being subjected to the measurements of the 2-year visit.

\subsection{Measurements}

\subsubsection{Clinical assessment}

All study participants received usual care, including standard anteroposterior and lateral radiographs of the injured wrist at the emergency room visit and at the physicians' discretion during followup. Fracture classification based on these images (i.e. AO-classification, comminuted vs. non-comminuted, intra- vs. extra-articular, reduction vs. no reduction) was retrieved from the patients' medical records.

Table 1

Inclusion and exclusion criteria.

$$
\begin{aligned}
& \text { Inclusion criteria } \\
& \text { - Postmenopausal women } \\
& \text { - Older than } 50 \text { years } \\
& \text { - Distal radius fracture } \\
& \text { - Treated by cast immobilization } \\
& \text { - Willing and able to participate } \\
& \text { - Provides informed consent } \\
& \text { Exclusion criteria } \\
& \text { - Previous surgery at current fracture location } \\
& \text { - Active or suspected infection in past } 3 \text { months } \\
& \text { - Malignant disease in past } 12 \text { months } \\
& \text { - Neuromuscular or neurosensory condition } \\
& \text { - Known systemic or metabolic bone disease } \\
& \text { - Active inflammatory disease } \\
& \text { - Oral glucocorticoid use in past } 12 \text { months } \\
& \text { - Mental incompetence } \\
& \text { - Severe concurrent joint involvement } \\
& \text { - Participation in another distal radius trial }
\end{aligned}
$$

\subsubsection{Functional outcome}

Functional outcome at all visits was measured using the Dutch version of the Patient Rated Wrist Evaluation (PRWE) questionnaire $[13,14]$, a validated instrument to assess outcome after distal radius fractures [15]. The PRWE questionnaire consists of 15 items divided in a pain- and a function subset. The combined score ranges from 0 (no pain/disabilities) to 100 (worst pain/disabilities). PRWE results were clustered in categories according to severity as described elsewhere [16]: none/minimal $(0-20)$, mild (21-40), moderate (41-60), severe (61-80) and very severe (81-100).

\subsubsection{HR-pQCT measurements}

HR-pQCT-scans (XtremeCT-1, Scanco Medical AG, Switzerland) of the fracture region were performed at 1 to 2 weeks (visit 1 ), 3 to 4 weeks (visit 2) and 2 years (visit 5) post-fracture. Casts were saved after removal and temporarily reapplied during all follow-up scans. Images were acquired using the manufacturer's standard in vivo settings ( $82 \mu \mathrm{m}$ isotropic voxel size, $\mathrm{X}$-ray tube voltage $60 \mathrm{kVp}$ and tube current $0.9 \mathrm{~mA}, 100 \mathrm{~ms}$ integration time, 750 projections $/ 180^{\circ}$ ).

Scan length was set at $18 \mathrm{~mm} / 220$ slices, with the offset from the proximal edge of the lunate bone (reference point) being determined by the individual fracture location and kept the same for the follow-up scan. Due to the cast around the lower arm, the standard holder could not be utilized. Instead, a custom carbon cylinder with inflatable cushion (Pearltec AG, Schlieren, Switzerland) was used to hold the subject's arm during scanning and minimize motion artifacts [17]. Additionally, the unfractured contralateral radius was scanned during the first visit at a fixed region for all patients $(9.5 \mathrm{~mm}$ from the proximal edge of the lunate) with a scan length of 110 slices $(9 \mathrm{~mm})$ using the same custom holder.

Scans were quality-graded by the operator according to the criteria described by Pialat and colleagues [18]. When motion artifacts resulted in an image of insufficient quality (i.e. grade 4 or 5), the scan was repeated once. If the repeated scan was also of insufficient quality, the HR-pQCT data of that particular visit was not used for the analyses.

\subsection{Analyses}

\subsubsection{Image processing: bone density and microarchitecture}

HR-pQCT scans were processed and evaluated according to the standard patient evaluation protocol as provided by the manufacturer. In short, a semi-automatic contouring method was used to define the periosteal boundary surface of the distal radius. Then, a LaplaceHamming filter was applied (epsilon 0.5 and cut-off frequency 0.4 ) with subsequent normalization (range 0-1000) and global thresholding (threshold 400) to extract the voxels that represented mineralized tissue. Volumetric bone density $\left(\mathrm{mgHA} / \mathrm{cm}^{3}\right)$ was determined for the total region, and the trabecular and cortical region separately. The microarchitecture of the scanned region was analyzed by trabecular number $(1 / \mathrm{mm})$, thickness $(\mathrm{mm})$ and separation $(\mathrm{mm})$. These were all derived with a 3D ridge extraction method [19]. Cortical thickness was calculated with the cortical volume divided by the outer cortical surface.

\subsubsection{Micro-finite element analysis}

From the segmented HR-pQCT images, micro-finite element $(\mu \mathrm{FE})$ models were constructed where bone-representing voxels were converted into a brick element of the same size. The material properties assigned to these elements were similar as in earlier studies: [20,21] a Young's modules of $10 \mathrm{GPa}$ and a Poisson's ratio of 0.3 .

Bone stiffness was assessed by four virtual load cases: a high-friction compression test (prescribed displacement of $1 \%$ length change in axial direction), a rotation test around the longitudinal axis ( $0.01 \mathrm{rad})$ to estimate torsional stiffness, and finally two rotational tests around the sagittal and transversal axis ( $0.01 \mathrm{rad})$, which were combined to estimate bending stiffness [9]. 


\subsection{Statistical analysis}

Baseline characteristics of the study group were reported as median with first and third quartiles. The association between the clinical fracture characteristics as described by the attending physician and having a low (0-40) or moderate/high (41-100) PRWE score were assessed with the Mann-Whitney $U$ test. For the first and second visit, the association of HR-pQCT and $\mu$ FEA parameters with the 2-year PRWE score was evaluated with simple linear regression models. In addition, the change between the first two visits was calculated for each HRpQCT and $\mu$ FEA parameter and analyzed similarly. In accordance with the exploratory nature of this study, no correction for multiple testing was applied in order to not further decrease statistical power. All statistical analyses were performed in SPSS 24.0 (IBM Corp., Armonk, NY, USA) with a significance level of $\alpha=0.05$.

\section{Results}

Of the 18 patients who completed the first study [9,12], 2 were unable to participate in the 2-year follow-up: one patient was deceased and one was unable to provide informed consent due to Alzheimer's disease. In addition, one patient declined participation. Thus, 15 subjects were included for the long-term analyses with a mean time between fracture date and the last follow-up visit of 115 weeks (range 98-127 weeks). Patient characteristics are described in Table 2. Despite a repeat scan when the first scan of a visit was of insufficient quality, 7 out of 45 visits $(16 \%)$ produced a scan with motion grade 4 or 5 according to Pialat et al. [18] As a consequence, 38 scans were used in the statistical analyses ( $N=12$ for visits 1 and $5, N=14$ for visit 2 , and $N=11$ for change between visit 1 and 2).

\subsection{Functional long-term outcome in relation to fracture characteristics}

The functional outcome as measured with the PRWE questionnaire 2 years post-fracture showed that more than half of the study participants experienced a good recovery, with 8 patients (53\%) reporting no or only mild pain and disability (a score between 0 and 40), vs. 7 patients (47\%) having moderate to very severe complaints (Fig. 1). This

\section{Table 2}

Baseline characteristics of the 15 postmenopausal women who completed the 2year follow-up visit.

\begin{tabular}{lrl}
\hline & Median & (Q1 to Q3) \\
\hline Age at time of fracture (years) & 64 & (55 to 69) \\
${\text { Weight }(\mathrm{kg})^{\mathrm{a}}}^{\mathrm{a}}$ & 67 & $(59$ to 73$)$ \\
BMI $\left(\mathrm{kg} / \mathrm{m}^{2}\right)^{\mathrm{a}}$ & 26 & $(24$ to 28$)$ \\
T-score total hip ${ }^{\mathrm{a}, \mathrm{b}}$ & -1.6 & $(-2.3$ to -0.9$)$ \\
T-score lumbar spine & -2.5 & $(-3.2$ to -1.0$)$ \\
25(OH)D level (nmol/l) & 58 & $(38$ to 95$)$
\end{tabular}

\begin{tabular}{lcl}
\hline & N & $\%$ \\
\hline 25(OH)D level < 50 nmol/1 & 5 & $(33 \%)$ \\
Prior bisphosphonate use & 1 & $(7 \%)$ \\
Bisphosphonate start after fracture $^{c}$ & 11 & $(73 \%)$ \\
AO fracture classification: & & \\
\hline - A (extraarticular) & 7 & $(47 \%)$ \\
- B (partial articular) & 0 & $(0 \%)$ \\
- C (complete articular) & 8 & $(53 \%)$ \\
\hline
\end{tabular}

${ }^{\text {a }}$ Weight, BMI (body mass index) and T-scores were available for 14 patients.

b Total hip T-score was missing for 1 additional patient due to bilateral hip prostheses.

c Independent of study participation, patients were simultaneously screened at the fracture liaison service to determine the indication for starting a bisphosphonate.

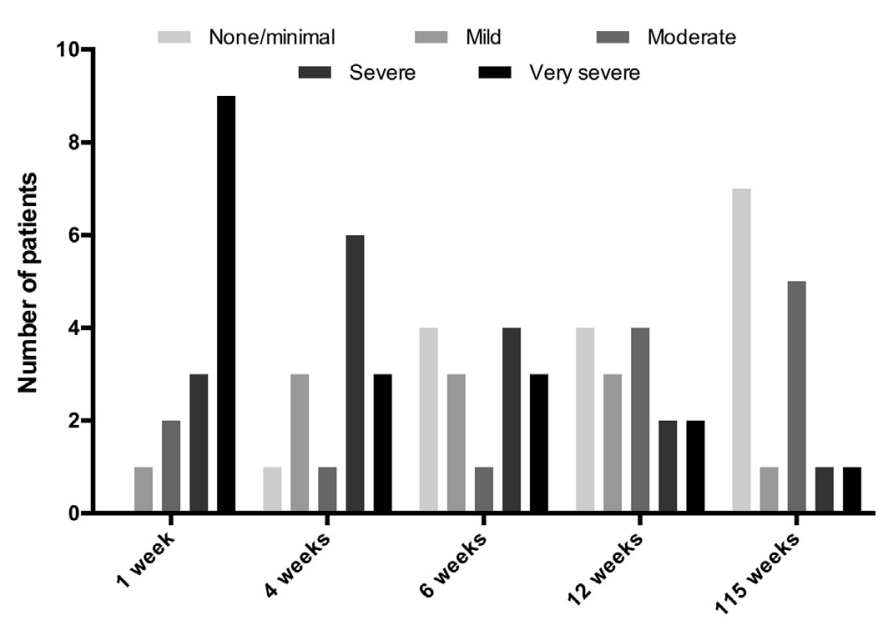

Time post-fracture (weeks)

Fig. 1. Pain and disability after a distal radius fracture, measured and classified according to the PRWE score [16]: $0-20=$ none $/$ minimal; $21-40=$ mild: $41-60=$ moderate; $61-80=$ severe; $81-100=$ very severe.

group also included a patient who developed complex regional pain syndrome (CRPS) during fracture healing [22].

PRWE score at 2 years post-fracture did not differ between extra- vs. intra-articular fractures as classified on conventional radiographs (AO type A vs. type C: median 12 vs. $35, \mathrm{p}=0.61$; the study population contained no type B fractures), comminuted vs. non-comminuted fractures (median 11 vs. $48, \mathrm{p}=0.75$ ) or fractures that required reduction vs. fractures that did not (median 22 vs. $24, \mathrm{p}=0.27$ ). Further exploratory analyses of the distribution of baseline characteristics according to functional outcome 2 years post-fracture did not reveal meaningful associations (data not shown), however it should be noted that the number of patients in the resulting subgroups were small.

\subsection{Functional long-term outcome in relation to HR-pQCT measurements}

Two years post-fracture, PRWE score was significantly related to early torsional and bending stiffness but not with early bone density, micro-architecture, geometry or compression stiffness of the fracture region or their early changes (Table 3, Fig. 2).

Up to $54 \%$ of the PRWE score 2 years post-fracture was explained by torsional or bending strength at the second visit, 3 to 4 weeks after the fracture. Based on the regression analysis, a $50 \mathrm{kNmm} / \mathrm{rad}$ higher torsional stiffness during the early stages of fracture healing translated into a decrease of 10 points on the PRWE questionnaire 2 years post-fracture.

These results were unaffected by including bisphosphonate use or $25(\mathrm{OH}) \mathrm{D}$ level as covariates in the statistical model. Of note, the results were similar regardless of including or excluding the patient with CRPS in the analyses (data not shown). No statistically significant associations between (early) longitudinal changes and long-term functional outcome were detected. Additionally, there was no significant association between the baseline measurements at the contralateral unfractured radius and long-term function, nor between long-term fracture region HR-pQCT results and PRWE-score at the 2-year visit (Supplemental Table 1).

\section{Discussion}

Previously, we described the healing of distal radius fractures from a strength perspective, including a comparison with the unfractured contralateral side [10]. In this study, we investigated the relation of HRpQCT-derived bone parameters after a distal radius fracture with functional outcome 2 years post-fracture. Our main finding was that a 
Table 3

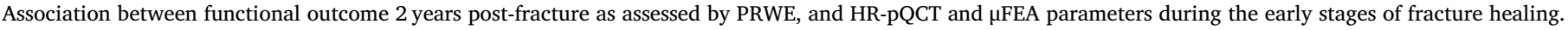
Statistically significant results $(\alpha=0.05)$ are denoted in bold.

\begin{tabular}{|c|c|c|c|c|c|c|c|c|c|c|c|c|}
\hline & \multicolumn{4}{|c|}{ Visit 1 (1-2 weeks post-fracture) } & \multicolumn{4}{|c|}{ Visit 2 (3-4 weeks post-fracture) } & \multicolumn{4}{|c|}{$\Delta$ visit 1 - visit 2} \\
\hline & \multicolumn{2}{|c|}{ B $(95 \%$ CI $)$} & \multicolumn{2}{|c|}{$\beta$ (p-value) } & \multicolumn{2}{|c|}{ B $(95 \% \mathrm{CI})$} & \multicolumn{2}{|c|}{$\beta$ (p-value) } & \multicolumn{2}{|c|}{ B $(95 \% \mathrm{CI})$} & \multicolumn{2}{|c|}{$\beta$ (p-value) } \\
\hline \multicolumn{13}{|l|}{ Density parameters } \\
\hline Total & 0.00 & $(-0.39$ to 0.39$)$ & 0.00 & $(0.995)$ & -0.06 & $(-0.45$ to 0.32$)$ & -0.10 & $(0.721)$ & -0.51 & $(-2.62$ to 1.60$)$ & -0.18 & $(0.598)$ \\
\hline Cortical & -0.02 & $(-0.21$ to 0.18$)$ & -0.06 & $(0.855)$ & -0.07 & $(-0.22$ to 0.09$)$ & -0.26 & $(0.362)$ & -0.83 & $(-3.08$ to 1.41$)$ & -0.27 & $(0.421)$ \\
\hline Trabecular & 0.14 & $(-0.58$ to 0.86$)$ & 0.13 & $(0.682)$ & 0.20 & $(-0.45$ to 0.86$)$ & 0.19 & $(0.507)$ & -0.55 & $(-2.80$ to 1.71$)$ & -0.18 & $(0.598)$ \\
\hline \multicolumn{13}{|c|}{ Micro-architectural parameters } \\
\hline Trabecular number & 24.5 & $(-18.8$ to 67.8$)$ & 0.37 & $(0.236)$ & 13.4 & $(-29.8$ to 56.5$)$ & 0.19 & $(0.512)$ & 36.7 & $(-62.5$ to 135.8$)$ & 0.27 & $(0.424)$ \\
\hline Trabecular thickness & -575 & $(-1868$ to 717$)$ & -0.30 & $(0.345)$ & -111 & $(-1955$ to 1733$)$ & -0.04 & $(0.898)$ & -1232 & $(-3789$ to 1325$)$ & -0.34 & $(0.304)$ \\
\hline Trabecular separation & -75 & $(-217$ to 66$)$ & -0.35 & $(0.264)$ & -62 & $(-242$ to 119$)$ & -0.21 & $(0.470)$ & -48 & $(-409$ to 313$)$ & -0.10 & $(0.769)$ \\
\hline \multicolumn{13}{|l|}{ Geometric parameters } \\
\hline Cortical thickness & -6.9 & $(-112.9$ to 99.1$)$ & -0.05 & $(0.887)$ & -30.0 & $(-124.8$ to 64.8$)$ & -0.20 & $(0.504)$ & 291.0 & $(-418.6$ to 1001$)$ & 0.30 & $(0.378)$ \\
\hline Cortical perimeter & 0.39 & $(-1.06$ to 1.84$)$ & 0.19 & $(0.562)$ & 0.22 & $(-0.79$ to 1.24$)$ & 0.14 & $(0.639)$ & -3.64 & $(-7.55$ to 0.26$)$ & -0.58 & $(0.064)$ \\
\hline \multicolumn{13}{|l|}{ Biomechanical parameters } \\
\hline Compression stiffness & -0.61 & $(-3.55$ to 2.34$)$ & -0.14 & $(0.656)$ & -0.79 & $(-3.22$ to 1.64$)$ & -0.20 & $(0.492)$ & -0.16 & $(-8.95$ to 8.63$)$ & -0.01 & $(0.968)$ \\
\hline Torsional stiffness & -0.13 & $(-0.27$ to 0.01$)$ & -0.54 & $(0.072)$ & -0.20 & $(-0.32$ to -0.07$)$ & -0.70 & $(0.006)$ & -0.01 & $(-0.39$ to 0.37$)$ & -0.03 & (0.939) \\
\hline Bending stiffness & -0.09 & $(-0.17$ to -0.01$)$ & -0.61 & $(0.035)$ & -0.11 & $(-0.18$ to -0.05$)$ & -0.74 & $(0.003)$ & 0.00 & $(-0.18$ to 0.18$)$ & -0.02 & (0.963) \\
\hline
\end{tabular}

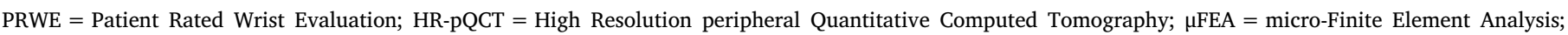
$\mathrm{B}=$ regression coefficient (unstandardized); $\beta=$ standardized regression coefficient; $\mathrm{CI}=$ confidence interval.

higher torsional or bending stiffness of the fracture region at week 3-4 post-fracture was associated with lower long-term pain and disability (PRWE) scores at 2 years. In contrast, no associations were found between long-term functional outcome and bone micro-architecture or stiffness at the healed fracture region 2 years post-fracture, nor with the contralateral unfractured distal radius at time of fracture. This indicates that the torsional or bending strength obtained in the early phase of fracture healing, but not the pre-fracture bone structure or strength, are significant determinants for long-term functional outcome.

An interesting observation is that compression stiffness was not associated with 2-year functional outcome. Since torsional and bending stiffness depend on the cortical bone perimeter and structural integrity more than compression stiffness [23] (Fig. 3), these results suggest that a larger perimeter and better cortical integrity at an early stage of healing are the reasons for a better outcome.

Previous studies have reported an association between injury compensation, educational level and radial shortening with 1-year functional outcome after a distal radius fracture [16,24]. These factors explained $25 \%$ of the observed variance in the functional outcome, whereas in our dataset torsional or bending stiffness at 3-4 weeks postfracture explained approximately half of PRWE scores 2 years postfracture.

The minimal clinically important difference for the PRWE score after distal radius fractures was reported to be 11.5 points [25]. Based on the regression equation in this study, such a difference is reflected by a $57.5 \mathrm{kNmm} / \mathrm{rad}$ separation in fracture region torsional stiffness between two patients 3-4 weeks post-fracture, a meaningful value considering the range of torsional stiffness observed at this visit $(\sim 200-500 \mathrm{kNmm} / \mathrm{rad})$.

Of interest, $\mu$ FEA results obtained at visit 2, 3-4 weeks after the fracture, showed a statistically significant association with functional outcome after 2 years, while the results of visit 1, 1-2 weeks after the fracture, were less striking. This could probably be explained by the smaller sample size at visit $1(N=12)$ due to a higher number of scans with significant motion artifacts compared to visit $2(N=14)$. A more likely explanation may be that $\mu \mathrm{FEA}$ within the first 2 weeks after the trauma overestimates the biomechanical parameters and that these are better characterized at 3-4 weeks post-fracture [9,26].

The finding that the HR-pQCT derived stiffness parameters at week $3-4$, but not the change of these parameters during early fracture healing, were associated with long-term functional outcome, contrasts with our earlier study, where it was shown that early changes in bone structure and strength are predictive of 12-week functional outcome [12]. However, these parameters might reveal different aspects of the fracture and its healing process: changes as measured with follow-up scans during the first weeks of fracture healing may reflect the biology of the healing response; a faster change, i.e. healing, due to the metabolism of the fracture region, is reflected by a lower pain score and better function score 12 weeks after the fracture. The final outcome however has not yet been achieved at that moment, for which the biological response at the early stages of fracture healing appears to be less important but could be determined primarily by the geometrical fracture characteristics such as the cortical integrity of the fracture as discussed above. As shown in this study, these are best determined at
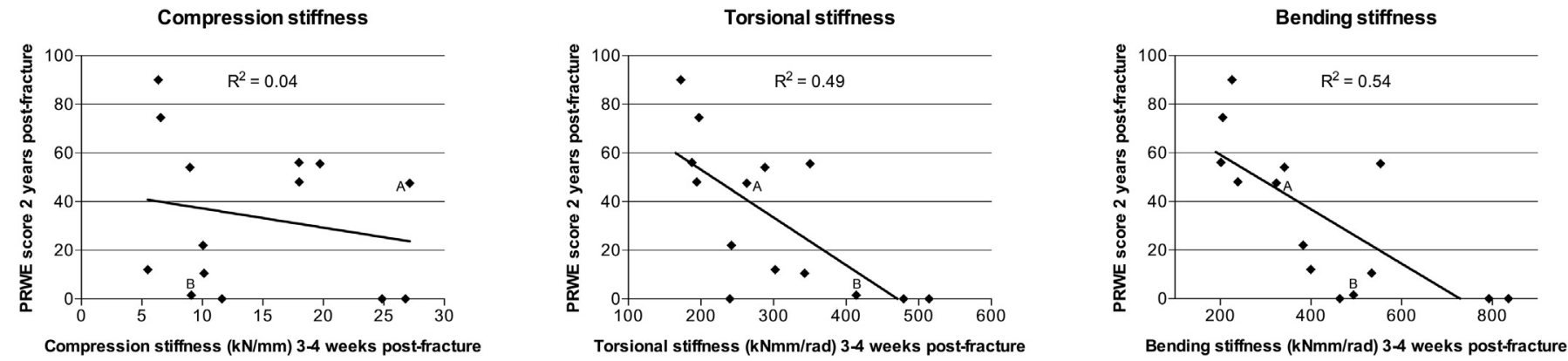

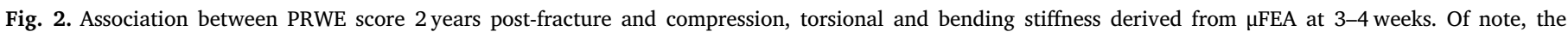
torsional- and bending stiffness graphs feature broken horizontal axes with a non-zero origin.

PRWE = Patient Rated Wrist Evaluation; A \& B mark the study participants shown in Fig. 4A \& B. 
A

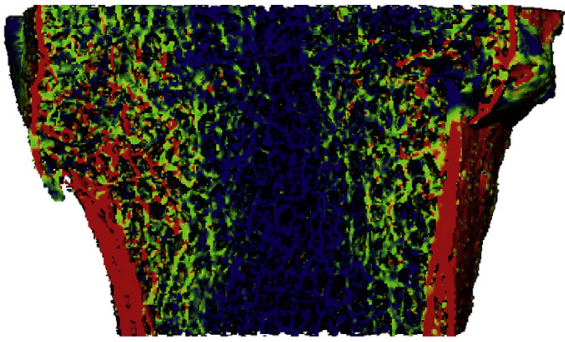

$6.0 \mathrm{e}-4 \quad 3.0 \mathrm{e}-4$
B

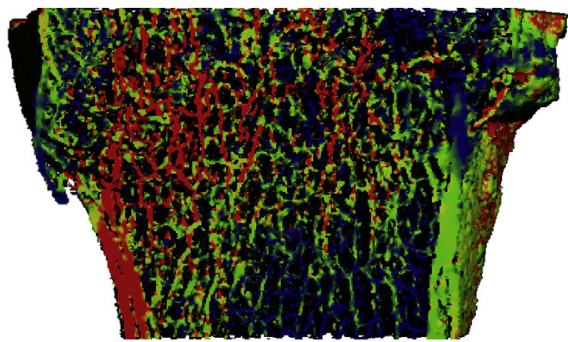

$0.08 \quad 0.50$

Fig. 3. Energy equivalent strain during torsional (A) and compression (B) loading of a distal radius fracture, illustrating the relatively greater contribution of cortical bone during the former, compared to the latter.

3-4 weeks post-fracture. Integrating these observations leads us to the concept visualized in Fig. 5: early HR-pQCT with $\mu$ FEA captures the geometrical fracture characteristics which are related to long-term outcome, whereas changes between these early measurements capture the metabolic healing rate related to 12-week outcome. Of note, the term geometrical fracture characteristics as used in this paper is not the same as the intra-articular aspects of a distal radius fracture, which are also important to functional recovery, but are not captured in the scanned region in this study.
Additionally, with respect to long-term outcome it is worth noting that a substantial number of distal radius fracture patients in our study population still experienced a significant degree of pain and disability. Although Fig. 1 shows that most of the patients had improved from severe to moderate pain/disability after 2 years compared to visit 1 , our data nevertheless indicates that nearly half of conservatively treated distal radius fracture patients should not be considered as fully recovered. This is a higher proportion than reported elsewhere, possibly explained by a different follow-up length [5].
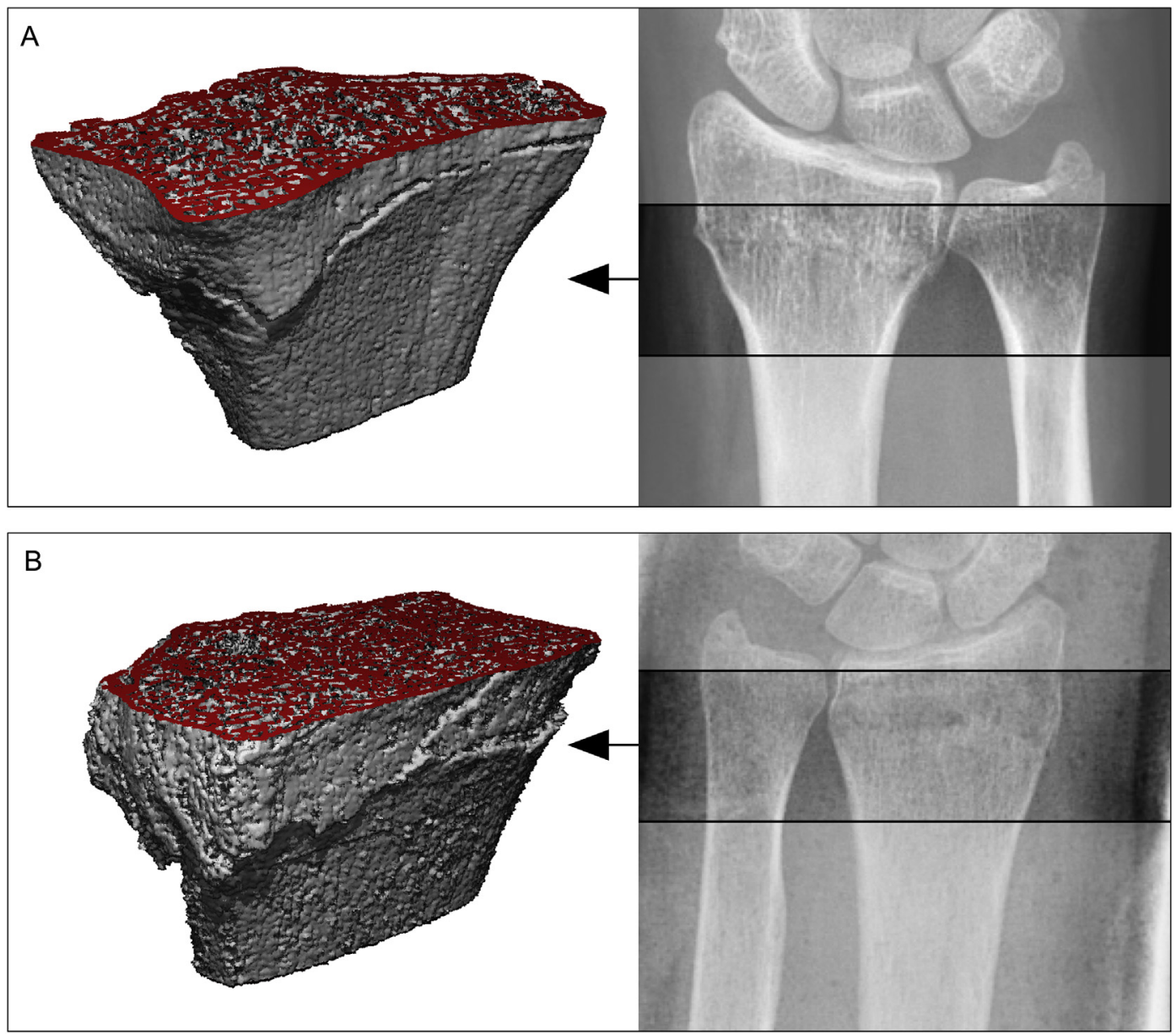

Fig. 4. Segmented 3-dimensional HR-pQCT reconstructions (1-2 weeks post-fracture) and conventional X-ray images (taken during the emergency room visit immediately after the fracture, HR-pQCT scan region is indicated), illustrating that $\mu$ FEA offers additional information beyond visual inspection; A: a low calculated stiffness and a high PRWE score after two years (= worse outcome) vs. B: a high calculated stiffness and a low PRWE score after two years (=better functional outcome). Figures correspond to patients A \& B marked in Fig. 2.

HR-pQCT $=$ High Resolution peripheral Quantitative Computed Tomography; $\mu$ FEA = micro-Finite Element Analysis; PRWE = Patient Rated Wrist Evaluation 


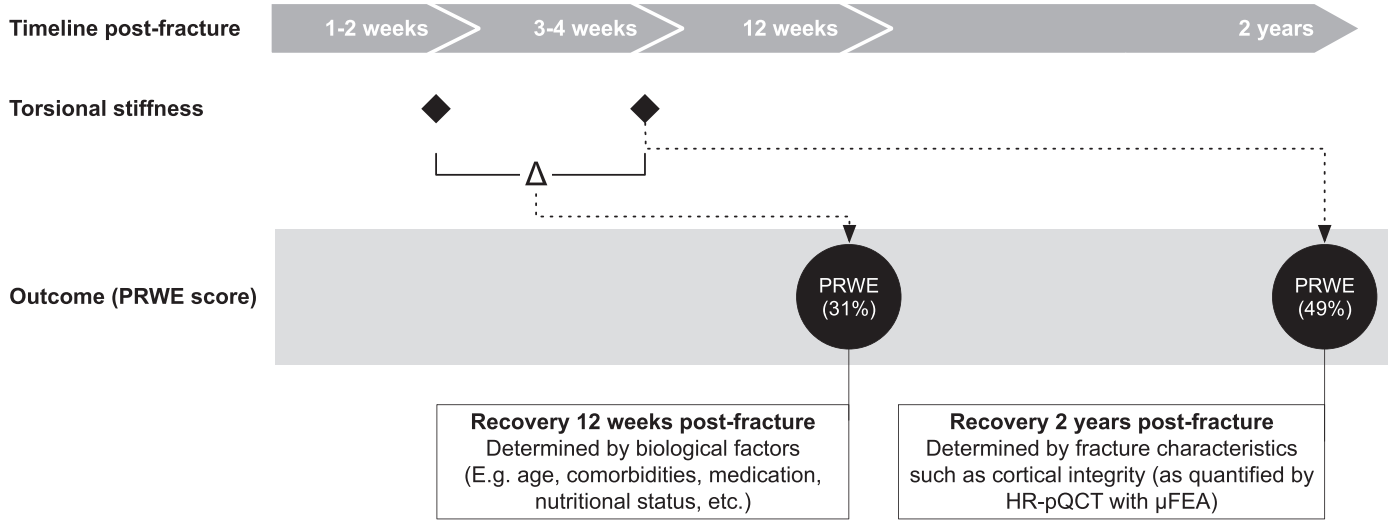

Fig. 5. Theoretical model describing the different aspects of a fracture and fracture healing: change in stiffness during fracture healing in the first 4 weeks reflects the biological response (associated with 12-week PRWE outcome), whereas the absolute stiffness value at 3-4 weeks mirrors the fracture characteristics as assessed using calculated bone-stiffness based on HR-pQCT (associated with 2-year PRWE outcome).

PRWE = Patient Rated Wrist Evaluation; HR-pQCT $=$ High Resolution peripheral Quantitative Computed Tomography; $\mu$ FEA = micro-Finite Element Analysis

Several limitations should be considered regarding this study. First, the exploratory nature (including not adjusting for multiple testing) and the small sample size restrict the generalization of our findings and require larger studies to verify these results. Furthermore, the clinical fracture classifications (e.g. intra- vs. extra-articular) contained as few as three patients per category, severely limiting the value of those analyses in this study. Second, $\mu$ FEA of a distal radius fracture, or metaphyseal fractures in general, has not yet been validated. Thus, we cannot currently state that the calculated stiffness parameters correspond to the actual biomechanical characteristics of the fracture region. Nevertheless, as our earlier studies have also shown, HR-pQCT and $\mu$ FEA are able to assess both initial fracture features as well as changes during fracture healing with an association with functional outcome $[9,12,22]$.

In conclusion, this exploratory study suggests that initial fracture characteristics as assessed with $\mu$ FEA based on HR-pQCT images are associated with long-term pain and functional impairment after a conservatively treated distal radius fracture in postmenopausal women. Follow-up studies with larger cohorts are needed to validate and replicate these results, including analyses of potential confounders at baseline. Furthermore, it remains to be elucidated if bone strength at 3-4 weeks post-fracture is only an indicator of long-term outcome, or if it is also a potential target for interventions. In the future, HR-pQCT with $\mu$ FEA could be of use as an early outcome measure (as surrogate for long-term functional outcome) in both clinical trials investigating fracture healing as well as in clinical practice, identifying those patients that are at risk of insufficient recovery after a distal radius fracture.

\section{Grant support}

This study was supported by a grant from The Weijerhorst Foundation (grant number WH2).

\section{Disclosures}

B. van Rietbergen is a consultant for Scanco Medical AG.

J.C. Arts is a board member of workgroup Biotechnology of the Dutch Orthopedic Association (NOV).

\section{Acknowledgements}

The authors would like to thank The Weijerhorst Foundation for their supporting grant and Liesbeth Jutten and Margareth Winants for their support with study logistics.

Authors' roles: Study design: JdJ, SB, JJCA, PCW, BvR, PPG, and
JvdB. Data collection: JdJ, SB, FLH. Data analysis: FLH and JdJ. Data interpretation: All authors. Drafting manuscript: FLH and JdJ. Revising manuscript content: All authors. Approving final version of manuscript: All authors. FLH takes responsibility for the integrity of the data analysis.

\section{Appendix A. Supplementary data}

Supplementary data to this article can be found online at https:// doi.org/10.1016/j.bone.2019.06.013.

\section{References}

[1] E.M. Curtis, R. van der Velde, R.J. Moon, J.P.W. van den Bergh, P. Geusens, F. de Vries, et al., Epidemiology of fractures in the United Kingdom 1988-2012: variation with age, sex, geography, ethnicity and socioeconomic status, Bone 87 (2016) 19-26 Jun.

[2] D.A. Eekman, S.H. van Helden, A.M. Huisman, H.J.J. Verhaar, I.E.M. Bultink, P.P. Geusens, et al., Optimizing fracture prevention: the fracture liaison service, an observational study, Osteoporos. Int. 25 (2) (2014) 701-709 (Feb).

[3] Brink PRG, Bransz N, Deijkers RLM, van Eerten PV, Kolkman S, van Loon J, et al. Richtlijn Distale Radius Fracturen. 2010. pp. 1-126.

[4] A. Beumer, M.M. McQueen, Fractures of the distal radius in low-demand elderly patients: closed reduction of no value in 53 of 60 wrists, Acta Orthop. Scand. 74 (1) (2003) 98-100 Feb.

[5] Z. Földhazy, H. Törnkvist, E. Elmstedt, G. Andersson, B. Hagsten, L. Ahrengart, Long-term outcome of nonsurgically treated distal radius fractures, J Hand Surg Am 32 (9) (2007) 1374-1384 Nov.

[6] D.J. Slutsky, Predicting the outcome of distal radius fractures, Hand Clin. 21 (3) (2005) 289-294. Aug.

[7] C.Y. Ng, M.M. McQueen, What are the radiological predictors of functional outcome following fractures of the distal radius? J Bone Joint Surg Br. British Editorial Society of Bone and Joint Surgery 93 (2) (2011) 145-150 Feb.

[8] D.M. Lichtman, R.R. Bindra, M.I. Boyer, M.D. Putnam, D. Ring, D.J. Slutsky, et al., Treatment of distal radius fractures, The Journal of the American Academy of Orthopaedic Surgeons 18 (2010) 180-189.

[9] J.J.A. de Jong, P.C. Willems, J.J. Arts, S.G.P. Bours, P.R.G. Brink, T.A.C.M. van Geel, et al., Assessment of the healing process in distal radius fractures by high resolution peripheral quantitative computed tomography, Bone 64 (2014) 65-74 Jul.

[10] J.J. de Jong, F.L. Heyer, J.J. Arts, M. Poeze, A.P. Keszei, P.C. Willems, et al., Fracture repair in the distal radius in postmenopausal women: a follow-up 2 years postfracture using HRpQCT, J. Bone Miner. Res. 31 (5) (2016) 1114-1122 May.

[11] J.F. Waljee, A. Ladd, J.C. MacDermid, T.D. Rozental, S.W. Wolfe, Distal radius outcomes consortium. A unified approach to outcomes assessment for distal radius fractures, J Hand Surg Am 41 (4) (2016) 565-573 Mar 5.

[12] U. Meyer, J.J. de Jong, S.G. Bours, S.G.P. Bours, A.P. Keszei, J.J. Arts, et al., Early changes in bone density, microarchitecture, bone resorption, and inflammation predict the clinical outcome 12 weeks after conservatively treated distal radius fractures: an exploratory study, J. Bone Miner. Res. 29 (9) (2014) 2065-2073 Sep.

[13] J.C. MacDermid, T. Turgeon, R.S. Richards, M. Beadle, J.H. Roth, Patient rating of wrist pain and disability: a reliable and valid measurement tool, J. Orthop. Trauma 12 (8) (1998) 577-586 Nov.

[14] S.M. Brink, E.G. Voskamp, P. Houpt, C.H. Emmelot, Psychometric properties of the Patient Rated Wrist/Hand Evaluation-Dutch Language Version (PRWH/E-DLV), J 
Hand Surg Eur 34 (4) (2009) 556-557 SAGE Publications. Aug.

[15] J. Goldhahn, F. Angst, B.R. Simmen, What counts: outcome assessment after distal radius fractures in aged patients, J. Orthop. Trauma 22 (8 Suppl) (2008) S126-S130 Sep.

[16] J.C. MacDermid, J.H. Roth, R.S. Richards, Pain and disability reported in the year following a distal radius fracture: a cohort study, BMC Musculoskelet. Disord. 4 (1) (2003) 24 Oct 31.

[17] J.J.A. de Jong, J.J. Arts, U. Meyer, P.C. Willems, P.P. Geusens, J.P.W. van den Bergh, et al., Effect of a cast on short-term reproducibility and bone parameters obtained from HR-pQCT measurements at the distal end of the radius, J. Bone Joint Surg. Am. 98 (5) (2016) 356-362 Mar 2.

[18] J.B. Pialat, A.J. Burghardt, M. Sode, T.M. Link, S. Majumdar, Visual grading of motion induced image degradation in high resolution peripheral computed tomography: impact of image quality on measures of bone density and micro-architecture, Bone 50 (1) (2012) 111-118 Jan.

[19] T. Hildebrand, A. Laib, R. Müller, J. Dequeker, P. Rüegsegger, Direct three-dimensional morphometric analysis of human cancellous bone: microstructural data from spine, femur, iliac crest, and calcaneus, J. Bone Miner. Res. 14 (7) (1999) 1167-1174 John Wiley and Sons and The American Society for Bone and Mineral Research (ASBMR). Jul.

[20] J.A. MacNeil, S.K. Boyd, Bone strength at the distal radius can be estimated from high-resolution peripheral quantitative computed tomography and the finite element method, Bone 42 (6) (2008) 1203-1213 Jun.

[21] A. Laib, P. Rüegsegger, Comparison of structure extraction methods for in vivo trabecular bone measurements, Comput. Med. Imaging Graph. 23 (2) (1999) 69-74 Mar.

[22] F.L. Heyer, J.J.A. de Jong, R.J.E.M. Smeets, J.J. Arts, M. Poeze, P.P. Geusens, et al., A case report of abnormal fracture healing as detected with high-resolution peripheral quantitative computed tomography, J. Clin. Densitom. 20 (4) (2017) 486-489 Jun 13.

[23] M.L. Bouxsein, D. Karasik, Bone geometry and skeletal fragility, Curr Osteoporos Rep 4 (2) (2006) 49-56 Jun.

[24] R. Grewal, J.C. MacDermid, J. Pope, B.M. Chesworth, Baseline predictors of pain and disability one year following extra-articular distal radius fractures, Hand (N Y) 2 (3) (2007) 104-111 Sep.

[25] M.M.J. Walenkamp, R.-J. de Muinck Keizer, J.C. Goslings, L.M. Vos, M.P. Rosenwasser, N.W.L. Schep, The minimum clinically important difference of the patient-rated wrist evaluation score for patients with distal radius fractures, Clin. Orthop. Relat. Res. 473 (10) (2015) 3235-3241 Oct.

[26] A.J. Arias-Moreno, K. Ito, B. Van rietbergen, Micro-finite element analysis will overestimate the compressive stiffness of fractured cancellous bone, J. Biomech. 49 (13) (2016) 2613-2618 Sep 6. 